\title{
A New Non-parametric Test Procedure for the Median of an Asymmetrical Population
}

\author{
Mohammad Ibrahim Ahmmad Soliman Gaafar \\ Department of Statistics, Faculty of Commerce, Alexandria University, Alexandria, Egypt
}

Email address:

aswanybakkar@yahoo.com

\section{To cite this article:}

Mohammad Ibrahim Ahmmad Soliman Gaafar. A New Non-parametric Test Procedure for the Median of an Asymmetrical Population. American Journal of Theoretical and Applied Statistics. Vol. 5, No. 6, 2016, pp. 376-386. doi: 10.11648/j.ajtas.20160506.17

Received: October 11, 2016; Accepted: October 25, 2016; Published: November 17, 2016

\begin{abstract}
This paper proposes and investigates the performance of a new non-parametric test procedure for the median of a non-normal population when the symmetry assumption is suspected. The new test procedure uses the Yeo-Johnson family of power transformations and the Shapiro-Wilk test of normality to modify the classical normal scores test. Under skewed models, simulation results show that the proposed test procedure is superior to all competitor tests under consideration in terms of preserving the empirical size of the test at its nominal level and also having higher empirical powers.
\end{abstract}

Keywords: Power Transformations, Non-parametric Procedures, The Normal Scores Test, The Wilcoxon Signed Ranks Test, The Sign Test, The Shapiro-Wilk Test

\section{Introduction}

Although statistical analysis techniques based on the normal theory are easy to carry on and interpret, it is generally believed that one will never observe a random sample that is exactly normally distributed. It is more practical to assume that the data have some sort of departure from normality which may be due to the existence of some outliers in one or both tails, or due to heavy tails or skewness of the distribution of the random variable.

Given that $y_{1}, y_{2}, \ldots, y_{n}$ is a random sample selected from a continuous population with an unknown median $\mathrm{M}$. We consider the problem of testing the null hypothesis $\left(\mathrm{H}_{\circ}: \mathrm{M}=\right.$ $M_{\circ}$ ) against composite alternative $H_{1}$. It is known that, under the normal model, the t-test is the uniformly most powerful unbiased test while the Fraser [4] normal Scores test is the locally most powerful rank test. When there is a severe departure from normality, there are two possible approaches to follow. The first is to correct the data for departure from normality, by applying some power transformation, and then apply one of the classical test procedures to the transformed data. The second is to consider some alternative procedures that do not require normality. The non-parametric sign, Wilcoxon signed ranks, and Baklizi [1] tests are three possible such alternatives.

Power transformations are considered when there is evidence that some of the model assumptions associated with a certain data analysis procedure are violated and such violation can be removed if the random variable is expressed in a different scale. Since tests of hypotheses are decision making problems, the main concern is to reach the proper decision no matter what the measurement scale is. The JohnDraper, the Halawa, and the Yeo-Johnson power transformations work on the deviations of observations from the centrality parameter, which is measured on the original scale of the data. Unlike the Box-Cox power transformation, this makes the one-sample tests of location applicable on the transformed scale using any of these three power transformations.

The problem of running tests of hypotheses after transforming the data was firstly tackled by Doksum and Wong [3]. They investigated the effect of the Box-Cox power transformation, introduced by Box and Cox [2], on the twosample t-test for the equality of the means of two independent populations. Assuming that the data of each population is positive, they applied the Box-Cox transformation to each sample separately. However, this approach cannot be applied to the one sample t-test. Also, this transformation does not apply to the paired t-test because of the possible negative differences. That's why Halawa [7] extended the family of modulus power transformations, introduced by John and Draper [11], to cover the case of 
skewed distributions. These two families are suitable for data distributed over the whole real line. In much a similar way like Doksum and Wong [3], Halawa [7] studied the effect of these two transformations on the powers of the one sample and the paired t-tests when applied to transformed data emerging from non-normal populations. He found that, when there is a true transformation to normality under these two families, the t-test based on the transformed data, using the normal maximum likelihood estimators of the transformation parameters, is asymptotically equivalent to the t-test based on the transformed data, using the true transformation. Also, in a simulation experiment he found that under several nonnormal experimental situations, the t-test computed from the transformed data has better power properties than the t-test computed from the original data.

This paper investigates the performance of the new proposed test procedure. In this case, we propose using the Yeo-Johnson power transformation to bring the data into approximate normality, then applying the normal scores test to the transformed data modified by the evidence of normality indicated by the magnitude of the P-value from the Shapiro-Wilk test applied to the transformed data.

A simulation study is conducted to compare the performance of the following eight test procedures:

1) The t-test computed from the original data, T(Orig).

2) The normal scores test based on the original data, NS(Orig).

3) The Wilcoxon signed ranks test based on the original data, W(Orig).

4) The sign test, Sign.

5) The Baklizi [1] test, Baklizi.

6) The t-test based on the transformed data using the Halawa power transformation, $\mathrm{T}(\mathrm{Hal})$.

7) The Wilcoxon signed ranks test based on the transformed data using the Halawa power transformation, W(Hal).

8) The proposed test procedure, Sol(YJ).

Section 2 introduces three families of power transformations that are applicable to all data sets, positive or negative. Section 3 introduces the Shapiro-Wilk test of normality used in the proposed new test procedure and the triples test for symmetry used in the Baklizi [1] test. Section 4 introduces seven competitor test procedures. Section 5 introduces the proposed new test procedure. Section 6 describes the design of the simulation experiment. Section 7 reports the main results and conclusions of the study.

\section{Families of Power Transformations}

The main goal of power transformations in the regression setting is to achieve linearity, constancy of variance, or some distributional assumption. However, under location-scale models, the main goal is to achieve normality or symmetry required for the validity of applying a certain analysis technique. This section presents three families of power transformations valid to handle both positive and negative data.

\subsection{The Family of Modulus Power Transformations}

John and Draper [11] introduced the family of modulus power transformations as

$$
\varphi(\mathrm{Y}-\mathrm{M}, \lambda)=\left\{\begin{array}{cc}
(-1)^{j}\left((|\mathrm{Y}-\mathrm{M}|+1)^{\lambda}-1\right) / \lambda & \lambda \neq 0 \\
(-1)^{j} \ln (|\mathrm{Y}-\mathrm{M}|+1) & \lambda=0
\end{array}\right.
$$

where (M) refers to the population median as a centrality parameter, and $\mathrm{j}=1$ for $\mathrm{Y} \leq \mathrm{M}$, and $\mathrm{j}=2$ for $\mathrm{Y}>\mathrm{M}$.

According to the results of Van Zwet [16], this transformation can be used to normalize distributions already possessing some measure of symmetry with $(0<\lambda<1)$ for data that is assumed to be symmetrically distributed with heavier tails than that of a normal distribution and to use it with $(\lambda>1)$ for data that is assumed to be symmetrically distributed with lighter tails than that of a normal distribution.

\subsection{The Two-Domain Family of Power Transformations}

For the two dimensional vector $\lambda=\left(\lambda_{1}, \lambda_{2}\right)^{t}$, Halawa [7] introduced the two-domain family of power transformations as

$$
h(Y-M, \underline{\lambda})=\left\{\begin{array}{cc}
(-1)^{\mathrm{j}}\left((|\mathrm{Y}-\mathrm{M}|+1)^{\lambda_{\mathrm{j}}}-1\right) / \lambda_{\mathrm{j}} & \lambda_{\mathrm{j}} \neq 0 \\
(-1)^{\mathrm{j}} \ln (|\mathrm{Y}-\mathrm{M}|+1) & \lambda_{\mathrm{j}}=0
\end{array}\right.
$$

where $\mathrm{j}=1$ for $\mathrm{Y} \leq \mathrm{M}$, and $\mathrm{j}=2$ for $\mathrm{Y}>\mathrm{M}$.

When $\left(\lambda_{1}=\lambda_{2}=\lambda\right)$, this transformation is reduced to the modulus family of power transformations.

The logic behind this transformation is that the sample observations may experience different patterns of departure from the hypothesized distribution on both tails. As a result, using different values of the transformation parameters is justifiable in such cases. So this transformation handles differently the sample data on both sides of a specified measure of location. This transformation is monotone increasing in $\mathrm{Y}$, so it preserves the order of the original data. The domain of this transformation is the whole real line, so it is applicable for all data sets (positive or negative). Also, when $\lambda_{1}$ and $\lambda_{2}$ are both nonnegative, the range of this transformation is the whole real line, so it theoretically validates the normality assumption.

Van Zwet [16] proved that a non-decreasing concave (convex) transformation of a random variable extends the lower (upper) part of the support and squeezes the upper (lower) part. Accordingly, $\mathrm{h}(\mathrm{Y}-\mathrm{M}, \underline{\lambda})$ decreases the skewness to the right when $\lambda_{1} \in(1, \infty)$ and $\lambda_{2} \in(0,1)$ while it decreases the skewness to the left when $\lambda_{1} \in(0,1)$ and $\lambda_{2} \in(1, \infty)$.

\subsection{The Yeo-Johnson Family of Power Transformations}

Yeo and Johnson [17] introduced the following family of power transformations:

$$
\psi(\mathrm{Y}-\mathrm{M}, \lambda)=\left\{\begin{array}{cc}
{\left[1-(\mathrm{M}-\mathrm{Y}+1)^{2-\lambda}\right] /(2-\lambda)} & \text { if }(\mathrm{Y} \leq \mathrm{M}, \lambda \neq 2) \\
-\ln (\mathrm{M}-\mathrm{Y}+1) & \text { if }(\mathrm{Y} \leq \mathrm{M}, \lambda=2) \\
{\left[(\mathrm{Y}-\mathrm{M}+1)^{\lambda}-1\right] / \lambda} & \text { if }(\mathrm{Y}>M, \lambda \neq 0) \\
\ln (\mathrm{Y}-\mathrm{M}+1) & \text { if }(\mathrm{Y}>M, \lambda=0)
\end{array}\right.
$$


According to the results of Van Zwet [16], this transformation decreases the skewness to the right when $\lambda \in(0,1)$ while it decreases the skewness to the left when $\lambda \in(1, \infty)$.

It has to be noted that the Yeo-Johnson family of power transformations is a special case of the two-domain family of power transformations when $\left(\lambda_{1}=2-\lambda\right.$ and $\left.\lambda_{2}=\lambda\right)$.

\section{Preliminary Tests}

\subsection{The Shapiro-Wilk Test}

Let $y_{(1)}, y_{(2)}, y_{(3)}, \ldots \ldots, y_{(n)}$ denote the order statistics corresponding to the random sample $y_{1}, y_{2}, y_{3}, \ldots \ldots, y_{n}$ and let $\mu_{(i)}$ denote the expected value of the $i^{\text {th }}$ standard normal order statistic. The Shapiro-Wilk test statistic is defined as

$$
\mathrm{W}=\left[\sum_{i=1}^{n} a_{i} y_{(i)}\right]^{2} / \sum_{i=1}^{n}\left(y_{i}-\bar{y}\right)^{2}
$$

The coefficients $\left\{\mathrm{a}_{\mathrm{i}}\right\}$, the normalized best linear unbiased coefficients, depend on the covariance matrix of the standard normal order statistics. However, Shapiro and Wilk [15] adopted the following approximation that does not require explicit expressions for the elements of this matrix.

$$
\hat{a}_{i}^{*}=\left\{\begin{array}{cc}
2 \mu_{(i)} & i=2,3, \ldots \ldots, n-1 . \\
\sqrt{\frac{\hat{a}_{1}^{2}}{1-2 \hat{a}_{1}^{2}} \sum_{i=2}^{n-1} \hat{a}_{i}^{* 2}} & i=1, n .
\end{array}\right.
$$

With

$$
\hat{a}_{1}^{2}=\hat{a}_{n}^{2}=\left\{\begin{array}{cc}
g(n-1) & n \leq 20 \\
g(n) & n>20
\end{array}\right.
$$

And

$$
g(n)=\frac{\Gamma\left(\frac{n+1}{2}\right)}{\sqrt{2} \Gamma(1+0.5 n)}
$$

It has to be noted that $\hat{a}_{1}^{*}$ in (5) should be taken with a negative sign, and the approximated weights should be normalized such that: $\sum_{i=1}^{n} \hat{a}_{i}^{* 2}=1$.

For $\mathrm{n} \leq 400$, exact values of $\mu_{(i)}$ given by Harter [9]. To compute the significance level, Shapiro and Wilk [15] approximated the null distribution of $\mathrm{W}$ for $(7 \leq n \leq 50)$ using the following transformation:

$$
Z=\theta+\delta \ln [(\mathrm{W}-\varepsilon) /(1-\mathrm{W})]
$$

Where $Z$ is a standard normal deviate, and $\theta, \delta$ and $\varepsilon$ are constants for each $n$.

Royston [14] considered a different normalizing transformation for approximating the null distribution of $\mathrm{W}$, valid for sample sizes up to 2000 , defined as

$$
Z_{R}=\frac{\mathrm{U}-\mu_{\mathrm{U}}}{\sigma_{\mathrm{U}}}
$$

Where,

$$
\mathrm{U}=(1-\mathrm{W})^{\gamma}
$$

For $(7 \leq n \leq 20) \gamma, \ln \left(\mu_{\mathrm{U}}\right)$ and $\ln \left(\sigma_{\mathrm{U}}\right)$ are computed via the polynomials:

$\gamma=0.118898+0.133414 D+0.327907 D^{2}$

$\ln \left(\mu_{\mathrm{U}}\right)=-0.37542-0.492145 D-1.124332 D^{2}-0.199422 D^{3}$

$\ln \left(\sigma_{\mathrm{U}}\right)=-3.15805+0.729399 D+3.01855 D^{2}+1.558776 D^{3}$

$\mathrm{D}=\ln (n)-3$

For $(21 \leq n \leq 2000) \gamma, \ln \left(\mu_{\mathrm{U}}\right)$ and $\ln \left(\sigma_{\mathrm{U}}\right)$ are computed via the polynomials:

$$
\begin{aligned}
& \gamma=0.480385+0.318828 D-0.0241665 D^{3}+0.00879701 D^{4}+0.002989646 D^{5} \\
& \ln \left(\mu_{\mathrm{U}}\right)=-1.91487-1.37888 D-0.04183209 D^{2}-0.1066339 D^{3}-0.03513666 D^{4}-0.01504614 D^{5} \\
& \ln \left(\sigma_{\mathrm{U}}\right)=-3.73538-1.015807 D-0.331885 D^{2}+0.1773538 D^{3}-0.01638782 D^{4}-0.03215018 D^{5}+0.003852646 D^{6} \\
& \mathrm{D}=\ln (n)-5
\end{aligned}
$$

Large values of $Z_{R}$ imply departure from normality where $Z_{R}$ has a standard normal distribution under the null normal model.

\subsection{The Triples Test}

The Randles et al. [13] triples test for the symmetry of the distribution of the random variable $\mathrm{Y}$ about some unknown value is to reject the null hypothesis of symmetry if $|\mathrm{V}|>z_{\alpha / 2}$, where $z_{\alpha / 2}$ is the $\left(1-\frac{\alpha}{2}\right)$ quantile of the standard normal distribution and

$$
\begin{gathered}
\mathrm{V}=\frac{\mathrm{T}}{\mathrm{s}^{\prime}} \\
\mathrm{T}=\sum_{1 \leq i} \sum_{<j} \sum_{<k \leq n} f^{*}\left(y_{i}, y_{j}, y_{k}\right), \\
f^{*}\left(y_{i}, y_{j}, y_{k}\right)=\operatorname{sgn}\left(y_{i}+y_{j}-2 y_{k}\right)+\operatorname{sgn}\left(y_{i}+y_{k}-2 y_{j}\right)+\operatorname{sgn}\left(y_{j}+y_{k}-2 y_{i}\right),
\end{gathered}
$$




$$
\begin{aligned}
& \mathrm{S}^{2}=\left[\frac{(n-3)(n-4)}{(n-1)(n-2)} \sum_{t=1}^{n} B_{t}^{2}+\frac{(n-3)}{(n-4)} \sum_{s=1}^{n-1} \sum_{t=s+1}^{n} B_{s, t}^{2}+\frac{n(n-1)(n-2)}{6}-\left\{1-\frac{(\mathrm{n}-3)(\mathrm{n}-4)(\mathrm{n}-5)}{\mathrm{n}(\mathrm{n}-1)(\mathrm{n}-2)}\right\} \mathrm{T}^{2}\right], \\
& B_{t}=\sum_{j=t+1}^{n-1} \sum_{k=j+1}^{n} f^{*}\left(y_{t}, y_{j}, y_{k}\right)+\sum_{j=1}^{t-1} \sum_{k=t+1}^{n} f^{*}\left(y_{j}, y_{t}, y_{k}\right)+\sum_{j=1}^{t-2} \sum_{k=j+1}^{t-1} f^{*}\left(y_{j}, y_{k}, y_{t}\right), \\
& B_{s, t}=\sum_{j=1}^{s-1} f^{*}\left(y_{j}, y_{s}, y_{t}\right)+\sum_{j=s+1}^{t-1} f^{*}\left(y_{s}, y_{j}, y_{t}\right)+\sum_{j=t+1}^{n} f^{*}\left(y_{s}, y_{t}, y_{j}\right)
\end{aligned}
$$

\section{Competitor Test Procedures}

This section presents some test procedures and their exact or approximate distributions under the null hypothesis to be tested $\left(H_{\circ}: M=M_{\circ}\right)$.

\subsection{Tests Based on the Original Data}

Let $y_{1}, y_{2}, \ldots, y_{n}$ be a random sample selected from a population with median $\mathrm{M}$.

- When the sampled population is assumed to be normal:

1) the uniformly most powerful unbiased test statistic of the above hypothesis is given as:

$$
\mathrm{T}\left(\text { Orig) }=\frac{\sqrt{n}\left(\bar{y}-\mathrm{M}_{\circ}\right)}{s_{y}}\right.
$$

where $\bar{y}$ and $S_{y}$ denote the mean and the standard deviation of the sample observations respectively. Under $\mathrm{H}_{o}, \mathrm{~T}$ (Orig) has a t-distribution with (n-1) degrees of freedom.

2) the locally most powerful rank test of the above hypothesis is the Fraser [4] normal Scores test whose test statistic is given as

$$
\begin{gathered}
\mathrm{NS}_{\mathrm{F}}=\sum_{i=1}^{n} \mathrm{I}\left(y_{i}-\mathrm{M}_{\circ}\right) \times \mathrm{E}\left(|\mathrm{V}|_{\left(R_{\mathrm{i}}^{+}\right)}\right)= \\
\sum_{i=1}^{n} \mathrm{I}\left(y_{i}-\mathrm{M}_{\circ}\right) \times \mathrm{E}\left(\Phi^{-1}\left[\frac{1}{2}+\frac{1}{2} U_{\left(R_{\mathrm{i}}^{+}\right)}\right]\right)
\end{gathered}
$$

Where $\mathrm{V}$ is a standard normal variable, $\mathrm{R}_{i}^{+}(=$ $\left.\mathrm{R}\left(\left|y_{i}-\mathrm{M}_{\circ}\right|\right)\right)$ denotes the rank of the absolute deviation of the $\mathrm{i}^{\text {th }}$ sample observation from $\mathrm{M}_{o}, \mathrm{E}\left(|\mathrm{V}|_{(\mathrm{i})}\right)$ is the expected value of the $\mathrm{i}^{\text {th }}$ absolute value of the standard normal order statistic, $U_{(\mathrm{i})}$ is the $\mathrm{i}^{\text {th }}$ standard uniform order statistic, and $\mathrm{I}\left(y_{i}-\mathrm{M}_{\circ}\right)= \begin{cases}1 & \text { for } y_{i}>\mathrm{M}_{\circ} \\ 0 & \text { for } y_{i}<\mathrm{M}_{\circ}\end{cases}$

Under $\mathrm{H}_{0}$, the statistic $\mathrm{Z}_{\mathrm{F}}$ has approximately a standard normal distribution.

Where,

$$
\begin{gathered}
\mathrm{Z}_{\mathrm{F}}=\frac{\mathrm{NS}_{\mathrm{F}}-\mathrm{E}\left(\mathrm{NS}_{\mathrm{F}}\right)}{\sqrt{\operatorname{Var}\left(\mathrm{NS}_{\mathrm{F}}\right)}}, \\
\mathrm{E}\left(\mathrm{NS}_{\mathrm{F}}\right)=0.5 \sum_{i=1}^{n} \mathrm{E}\left(|\mathrm{V}|_{\left(R_{\mathrm{i}}^{+}\right)}\right), \\
\operatorname{Var}\left(\mathrm{NS}_{\mathrm{F}}\right)=0.25 \sum_{i=1}^{n}\left[\mathrm{E}\left(|\mathrm{V}|_{\left(R_{\mathrm{i}}^{+}\right.}\right)\right]^{2}
\end{gathered}
$$

3 ) the van der Waerden type of the asymptotically locally most powerful rank test of the above hypothesis has the following test statistic:

$$
\mathrm{NS}_{\mathrm{V}}=\sum_{i=1}^{n} \mathrm{I}\left(y_{i}-\mathrm{M}_{\circ}\right) \times \Phi^{-1}\left(\frac{1}{2}+\frac{\mathrm{R}\left(\left|y_{i}-\mathrm{M}_{\circ}\right|\right)}{2(\mathrm{n}+1)}\right)
$$

Under $\mathrm{H}_{0}$, the statistic $\mathrm{Z}_{\mathrm{V}}$ has approximately a standard normal distribution.

Where,

$$
\begin{gathered}
\mathrm{Z}_{\mathrm{V}}=\frac{\mathrm{NS}_{\mathrm{V}}-\mathrm{E}\left(\mathrm{NS}_{\mathrm{V}}\right)}{\sqrt{\operatorname{Var}\left(\mathrm{NS}_{\mathrm{V}}\right)}} \\
\mathrm{E}\left(\mathrm{NS}_{\mathrm{V}}\right)=0.5 \sum_{i=1}^{n} \Phi^{-1}\left(\frac{1}{2}+\frac{\mathrm{R}\left(\left|y_{i}-\mathrm{M}_{\mathrm{o}}\right|\right)}{2(\mathrm{n}+1)}\right) \\
\operatorname{Var}\left(\mathrm{NS}_{\mathrm{V}}\right)=0.25 \sum_{i=1}^{n}\left[\Phi^{-1}\left(\frac{1}{2}+\frac{\mathrm{R}\left(\left|y_{i}-\mathrm{M}_{\mathrm{o}}\right|\right)}{2(\mathrm{n}+1)}\right)\right]^{2}
\end{gathered}
$$

- When there is evidence that the sampled population is symmetric with heavier or lighter tails than those of a normal distribution, the Wilcoxon signed ranks test is a better choice. This test is based on ranking the absolute sample deviations from the hypothesized median $\mathrm{M}_{\circ}$, assigning each rank the corresponding deviation's sign, and then taking the sum of the signed positive ranks. Thus, the test statistic can be defined as:

$$
\mathrm{W}(\text { Orig })=\sum_{i=1}^{n} \mathrm{I}\left(y_{i}-\mathrm{M}_{\circ}\right) \times \mathrm{R}\left(\left|y_{i}-\mathrm{M}_{\circ}\right|\right)
$$

Under $\mathrm{H}_{\circ}$, the statistic $\mathrm{Z}_{1}^{*}$ has approximately a standard normal distribution.

Where,

$$
\begin{gathered}
\mathrm{Z}_{1}^{*}=\frac{(\mathrm{w}(\text { Orig) }) \mathrm{E}(\mathrm{W}(\text { Orig })))-0.5 \times \operatorname{sgn}(\mathrm{w}(\text { Orig })-\mathrm{E}(\mathrm{w}(\text { Orig }))}{\sqrt{\operatorname{Var}(\mathrm{W}(\text { Orig }))}}, \\
\mathrm{E}(\mathrm{W}(\text { Orig }))=0.5 \sum_{i=1}^{n} \mathrm{R}\left(\left|y_{i}-\mathrm{M}_{\circ}\right|\right), \\
\operatorname{Var}(\mathrm{W}(\text { Orig }))=0.25 \sum_{i=1}^{n}\left[\mathrm{R}\left(\left|y_{i}-\mathrm{M}_{\circ}\right|\right)\right]^{2}
\end{gathered}
$$

- When there is evidence about significant departure from symmetry the sign test is a good choice. The test statistic is based on the number, $\mathrm{k}$, of positive deviations from the hypothesized median $M_{\circ}$.

$$
\mathrm{K}=\sum_{i=1}^{n} \mathrm{I}\left(y_{i}-\mathrm{M}_{\mathrm{o}}\right)
$$

Under $\mathrm{H}_{\circ}$, $\mathrm{k}$ has a binomial distribution Bin (n, 0.5).

- Another choice when there is evidence about significant departure from symmetry was introduced by Baklizi [1].

This test is based on modifying the Wilcoxon scores according to the evidence of asymmetry of the population present in the data as indicated by the magnitude of the P-value from the triples test of symmetry. Given that the P-value of the triples test of symmetry is "p", Baklizi [1] proposed the following test statistic: 


$$
\mathrm{A}=\sum_{i=1}^{n} \mathrm{I}\left(y_{i}-\mathrm{M}_{\mathrm{o}}\right) \times\left[\mathrm{R}\left(\left|y_{i}-\mathrm{M}_{\circ}\right|\right)\right]^{p}
$$

Under $\mathrm{H}_{\mathrm{o}}$, the statistic $Z_{B a k}$ has approximately a standard normal distribution.

Where,

$$
\begin{gathered}
Z_{B a k}=\frac{A-\mathrm{E}(A \mid p)}{\sqrt{\operatorname{Var}(A \mid p)}}, \\
\mathrm{E}(A \mid p)=0.5 \sum_{i=1}^{n}\left[\mathrm{R}\left(\left|y_{i}-\mathrm{M}_{\circ}\right|\right)\right]^{p}, \\
\operatorname{Var}(A \mid p)=0.25 \sum_{i=1}^{n}\left[\mathrm{R}\left(\left|y_{i}-\mathrm{M}_{\circ}\right|\right)\right]^{2 p}
\end{gathered}
$$

\subsection{Tests Based on the Transformed Data}

- Halawa [7] obtained the maximum likelihood estimators, $\hat{\lambda}_{1}$ and $\hat{\lambda}_{2}$, of the two-domain transformation parameters $\lambda_{1}$ and $\lambda_{2}$ as an iterative solution of the following nonlinear system of equations,

$$
\begin{gathered}
{\left[\frac{-1}{\widehat{\sigma}^{2}} \sum_{\mathrm{i}=1}^{\mathrm{n}} \mathrm{h}\left(y_{i}-\mathrm{M}, \underline{\lambda}\right) \times \frac{\partial \mathrm{h}}{\partial \lambda_{\mathrm{j}}}+\sum_{\mathrm{i}=1}^{\mathrm{n}} \ln \left(\left|y_{i}-\mathrm{M}\right|+1\right)\right] \times \mathrm{I}_{\mathrm{j}}=0} \\
\forall \mathrm{i}=1,2,3, \ldots \ldots \ldots \ldots, \mathrm{n} ; \mathrm{j}=1,2 .
\end{gathered}
$$

Where

$$
\begin{aligned}
& \widehat{\sigma}^{2}=\frac{1}{n} \sum_{\mathrm{i}=1}^{\mathrm{n}} \mathrm{h}^{2}\left(y_{i}-\mathrm{M}, \underline{\lambda}\right)
\end{aligned}
$$

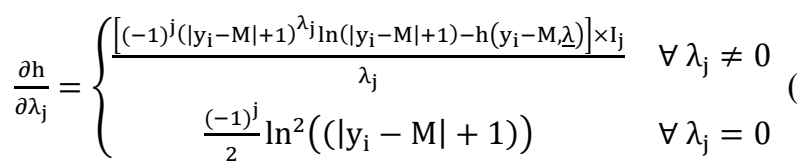

$$
\begin{aligned}
& I_{2}=\left\{\begin{array}{cc}
1 & \text { if } y_{i}>M \\
0 & \text { otherwise }
\end{array}\right.
\end{aligned}
$$

Under $H_{\circ}$, we replace $M$ by $M_{\circ}$ in the above expressions.

Let $\mathrm{h}\left(y_{i}-\mathrm{M}_{\circ}, \underline{\hat{\lambda}}\right), i=1,2, \ldots \ldots, n$, denote the transformed sample deviations from $M_{\circ}$ using the two domain power transformation. Also, let $\overline{\mathrm{h}}\left(y_{i}-\mathrm{M}_{\circ}, \underline{\hat{\lambda}}\right)$ and $S_{\mathrm{h}}$ denote their mean and standard deviation respectively. The t-test statistic on the transformed scale, proposed by Halawa [7], is then defined as:

$$
\mathrm{T}(\mathrm{Hal})=\sqrt{n} \overline{\mathrm{h}}\left(y_{i}-\mathrm{M}_{\circ}, \underline{\hat{\lambda}}\right) / S_{\mathrm{h}}
$$

The performance of the test statistic $\mathrm{T}(\mathrm{Hal})$, using the data-based estimators of the two-domain transformation parameters was investigated by Halawa [7] assuming that its null distribution has a t-distribution with (n-1) degrees of freedom.

- Halawa [8] proposed using the two-domain transformation to bring the data into approximate symmetry, then applying the Wilcoxon signed ranks test to the transformed data. Hence, the proposed Wilcoxon signed ranks test statistic on the transformed scale can be calculated as:

$$
\mathrm{W}(\mathrm{Hal})=\sum_{i=1}^{n} \mathrm{I}\left(y_{i}-\mathrm{M}_{\circ}\right) \times \mathrm{R}\left(\left|\mathrm{h}\left(y_{i}-\mathrm{M}_{\circ}, \underline{\hat{\lambda}}\right)\right|\right)
$$

where $\mathrm{R}\left(\left|\mathrm{h}\left(y_{i}-\mathrm{M}_{\circ}, \underline{\hat{\lambda}}\right)\right|\right)$ denote the rank of the absolute transformed deviation of the $i^{\text {th }}$ sample observation from $M_{\text {。 }}$. using the Halawa power transformation.

Under $\mathrm{H}_{\circ}$, the statistic $\mathrm{Z}_{\mathrm{H}}^{*}$ has approximately a standard normal distribution.

Where,

$$
\begin{gathered}
\mathrm{Z}_{\mathrm{H}}^{*}=\frac{(\mathrm{w}(\text { Hal })-\mathrm{E}(\mathrm{W}(\text { Hal })))-0.5 \times \operatorname{sgn}(\mathrm{W}(\text { Hal })-\mathrm{E}(\mathrm{W}(\text { Hal }))}{\sqrt{\operatorname{Var}(\mathrm{W}(\mathrm{Hal}))}}, \\
\mathrm{E}(\mathrm{W}(\text { Hal }))=0.5 \sum_{i=1}^{n} \mathrm{R}\left(\left|\mathrm{h}\left(y_{i}-\mathrm{M}_{\circ}, \underline{\hat{\lambda}}\right)\right|\right), \\
\operatorname{Var}(\mathrm{W}(\text { Hal }))=0.25 \sum_{i=1}^{n}\left[\mathrm{R}\left(\left|\mathrm{h}\left(y_{i}-\mathrm{M}_{\circ}, \underline{\hat{\lambda}}\right)\right|\right)\right]^{2}
\end{gathered}
$$

\section{The Proposed Test Procedure}

The new procedure uses the Yeo-Johnson family of power transformations to bring the sample deviations from the hypothesized median $\left(\mathrm{M}_{\mathrm{o}}\right)$ into approximate normality. The transformed deviations are then tested for normality using the Shapiro-Wilk test and the p-value $(p)$ is calculated. The van der Waerden type of the normal scores test is then calculated based on the transformed deviations modified by the $p$-value of the Shapiro-Wilk test. Hence the proposed conditional test statistic can be represented as

$$
\operatorname{Sol}(\mathrm{YJ})=\sum_{i=1}^{n} \mathrm{I}\left(y_{i}-\mathrm{M}_{\mathrm{o}}\right) \times\left[\Phi^{-1}\left(\frac{1}{2}+\frac{\mathrm{R}\left(\left|\psi\left(y_{i}-\mathrm{M}_{\mathrm{o}}, \widehat{\lambda}\right)\right|\right)}{2(\mathrm{n}+1)}\right)\right]^{p}
$$

Under $\mathrm{H}_{0}$, it follows from the general theory of linear rank statistics (Randles\& Wolfe [12] p. 281) that the standardized version of the statistic $\operatorname{Sol}(\mathrm{YJ}), \mathrm{Z}_{\mathrm{V}}$, has a limiting standard normal distribution.

Where,

$$
\begin{gathered}
\mathrm{Z}_{\mathrm{V}}=\frac{\operatorname{Sol}(\mathrm{YJ})-\mathrm{E}(\operatorname{Sol}(\mathrm{YJ}) \mid p)}{\sqrt{\operatorname{Var}(\operatorname{Sol}(\mathrm{YJ}) \mid p)}}, \\
\mathrm{E}(\operatorname{Sol}(\mathrm{YJ}) \mid p)=0.5 \sum_{i=1}^{n}\left[\Phi^{-1}\left(\frac{1}{2}+\frac{\mathrm{R}\left(\left|\psi\left(y_{i}-\mathrm{M}_{\circ}, \widehat{\lambda}\right)\right|\right)}{2(\mathrm{n}+1)}\right)\right]^{p}, \\
\operatorname{Var}(\operatorname{Sol}(\mathrm{YJ}) \mid p)=0.25 \sum_{i=1}^{n}\left[\Phi^{-1}\left(\frac{1}{2}+\frac{\mathrm{R}\left(\left|\psi\left(y_{i}-\mathrm{M}_{\circ}, \widehat{\lambda}\right)\right|\right)}{2(\mathrm{n}+1)}\right)\right]^{2 \times p}
\end{gathered}
$$

\section{The Simulation Study}

The simulation study was executed using the Gauss software version 10. For each experimental situation described below, 5000 pseudo random samples, of sizes $n=25$ and $n=50$, were generated with initial seed 9831815 . These samples are then used to evaluate the empirical levels of the eight tests described in Sections 4 and 5. This number of replicates makes the upper limit of estimating the $5 \%$ nominal level within 0.007 at probability $99 \%$. That is, tests with empirical levels exceeding 0.057 are considered liberal and invalid for the underlying testing problem.

The null hypothesis $\left(\mathrm{H}_{\circ}: M=\mathrm{M}_{\circ}\right)$ is tested against both right-tailed and left-tailed alternatives. To evaluate the empirical powers, the medians of the simulated distributions are shifted gradually from the true value on both directions. 
The hypothesized values to be tested $\left(\mathrm{M}_{\circ}\right)$ are determined as $\mathrm{M}_{\circ}=\mathrm{M} \pm \delta \sigma$, where $\mathrm{M}$ and $\sigma$ are respectively, the median and the standard deviation of the sampled distribution and values of $\delta$ are selected to cover different spots over the range of the power function, $(0.05,1)$. The empirical power is computed as the percentage of times each test statistic exceeded its corresponding 5\% cutoff point.

The simulation study covered the standard normal model, the double exponential model, and some positively skewed models as described in table 1 .

Table 1. The probability distributions covered in the simulation study.

\begin{tabular}{llll}
\hline The distribution & Median $(\mathbf{M})$ & Standard deviation $(\boldsymbol{\sigma})$ & Coefficient of skewness \\
\hline Standard Normal & 0 & 1 & 0 \\
Double Exponential & 0 & 1.414 & 0 \\
Weibull (2.5) & 0.864 & 0.38 & 0.36 \\
Weibull (2) & 0.833 & 0.463 & 0.63 \\
Gamma (4) & 3.672 & 2 & 1 \\
Standard Extreme Value & 0.367 & 1.283 & 1.14 \\
Gamma (2) & 1.678 & 1.414 & 1.41 \\
Standard Lognormal & 1 & 2.1612 & 6.18 \\
\hline
\end{tabular}

\section{Results and Conclusions}

This section presents tables of empirical levels and powers of the proposed test procedure, Sol(YJ), and the other seven competitors described in Section 4. The rows with $\delta=0$ in each table represents the empirical level where the data is generated according to the null model.

Table 2 and table 3 present simulation results for the standard normal model, where the t-test is known to be uniformly most powerful, and for the double exponential model, where the Wilcoxon signed ranks test is known to be highly correlated with the maximum efficiency robust test (Gastwirth [6]). Under the normal model, although Sol(YJ) is trailing the three tests $\mathrm{T}$ (Orig), NS(Orig), and $\mathrm{W}$ (Orig), it cannot compete with them and there is a significant loss of power. Under the double exponential model, Sol(YJ) outperforms T(Orig), NS(Orig), Sign, T(Hal), and W(Hal), while it is at least as good as W(Orig) and Baklizi, especially with the larger sample size. The main conclusion to draw from this table is that when the evidence is in favor of the normality or the symmetry assumption, one should rely on the tests computed from the data on its original scale.

Table 2. Empirical levels and Powers of the Standard Normal distribution.

\begin{tabular}{|c|c|c|c|c|c|c|c|c|c|c|}
\hline $\mathbf{n}$ & $\delta$ & $\mathrm{H}_{1}$ & T(Orig) & NS(Orig) & W(Orig) & Sign & Baklizi & T(Hal) & W(Hal) & Sol(YJ) \\
\hline \multirow{12}{*}{25} & \multirow{2}{*}{0} & Right & 0.0522 & 0.0514 & 0.0476 & 0.0216 & 0.0454 & 0.026 & 0.0348 & 0.0436 \\
\hline & & Left & 0.0484 & 0.0486 & 0.0476 & 0.0202 & 0.0454 & 0.0256 & 0.0334 & 0.044 \\
\hline & \multirow{2}{*}{0.05} & Right & 0.0772 & 0.077 & 0.0732 & 0.0298 & 0.0706 & 0.0406 & 0.0528 & 0.0624 \\
\hline & & Left & 0.0798 & 0.0792 & 0.0762 & 0.0356 & 0.0698 & 0.0424 & 0.0576 & 0.071 \\
\hline & \multirow{2}{*}{0.10} & Right & 0.1228 & 0.1208 & 0.1158 & 0.0556 & 0.11 & 0.0686 & 0.0902 & 0.1048 \\
\hline & & Left & 0.1228 & 0.1232 & 0.116 & 0.0482 & 0.1064 & 0.0662 & 0.086 & 0.1034 \\
\hline & \multirow{2}{*}{0.20} & Right & 0.2458 & 0.2456 & 0.2306 & 0.1134 & 0.21 & 0.138 & 0.1718 & 0.1964 \\
\hline & & Left & 0.247 & 0.2488 & 0.2368 & 0.1144 & 0.2138 & 0.1402 & 0.1798 & 0.2076 \\
\hline & \multirow{2}{*}{0.30} & Right & 0.4302 & 0.4292 & 0.412 & 0.2054 & 0.3696 & 0.2648 & 0.3146 & 0.3504 \\
\hline & & Left & 0.4236 & 0.4222 & 0.4024 & 0.2024 & 0.3604 & 0.2606 & 0.3126 & 0.3452 \\
\hline & \multirow{2}{*}{0.40} & Right & 0.6078 & 0.6092 & 0.5874 & 0.3284 & 0.5334 & 0.4172 & 0.4788 & 0.5202 \\
\hline & & Left & 0.6202 & 0.6162 & 0.597 & 0.329 & 0.5434 & 0.4234 & 0.481 & 0.5228 \\
\hline \multirow{16}{*}{50} & \multirow{2}{*}{0.50} & Right & 0.7966 & 0.7902 & 0.7646 & 0.4732 & 0.7076 & 0.5868 & 0.6418 & 0.6902 \\
\hline & & Left & 0.7776 & 0.7688 & 0.755 & 0.4838 & 0.7052 & 0.5872 & 0.6408 & 0.6808 \\
\hline & \multirow{2}{*}{0} & Right & 0.0472 & 0.0482 & 0.0476 & 0.0342 & 0.049 & 0.0306 & 0.0416 & 0.0444 \\
\hline & & Left & 0.0478 & 0.0474 & 0.0448 & 0.0334 & 0.0484 & 0.0328 & 0.0404 & 0.0424 \\
\hline & \multirow{2}{*}{0.05} & Right & 0.0918 & 0.0922 & 0.0948 & 0.0612 & 0.0922 & 0.059 & 0.0784 & 0.0808 \\
\hline & & Left & 0.0952 & 0.0946 & 0.0968 & 0.0582 & 0.0904 & 0.0626 & 0.0798 & 0.084 \\
\hline & \multirow{2}{*}{0.10} & Right & 0.1702 & 0.17 & 0.1692 & 0.1108 & 0.1604 & 0.1108 & 0.1402 & 0.1408 \\
\hline & & Left & 0.1788 & 0.1768 & 0.171 & 0.1016 & 0.1594 & 0.1114 & 0.1348 & 0.1402 \\
\hline & \multirow{2}{*}{0.20} & Right & 0.411 & 0.41 & 0.3948 & 0.2458 & 0.3626 & 0.2826 & 0.3312 & 0.3328 \\
\hline & & Left & 0.4012 & 0.3996 & 0.393 & 0.2342 & 0.3618 & 0.2678 & 0.3188 & 0.321 \\
\hline & \multirow{2}{*}{0.30} & Right & 0.6752 & 0.6738 & 0.6626 & 0.4432 & 0.6094 & 0.5082 & 0.5674 & 0.565 \\
\hline & & Left & 0.6698 & 0.6628 & 0.6508 & 0.4342 & 0.5994 & 0.5056 & 0.5596 & 0.565 \\
\hline & \multirow{2}{*}{0.40} & Right & 0.8732 & 0.8684 & 0.8576 & 0.6486 & 0.8076 & 0.7312 & 0.779 & 0.7864 \\
\hline & & Left & 0.8804 & 0.879 & 0.8634 & 0.6504 & 0.8074 & 0.7288 & 0.7772 & 0.7736 \\
\hline & \multirow{2}{*}{0.50} & Right & 0.971 & 0.9702 & 0.9664 & 0.837 & 0.9324 & 0.8922 & 0.9186 & 0.9188 \\
\hline & & Left & 0.9706 & 0.9694 & 0.9648 & 0.83 & 0.933 & 0.8904 & 0.9176 & 0.9212 \\
\hline
\end{tabular}


Table 3. Empirical levels and Powers of the Double Exponential distribution.

\begin{tabular}{|c|c|c|c|c|c|c|c|c|c|c|}
\hline $\mathbf{n}$ & $\delta$ & $\mathrm{H}_{1}$ & T(Orig) & NS(Orig) & W(Orig) & Sign & Baklizi & T(Hal) & W(Hal) & Sol(YJ) \\
\hline \multirow{12}{*}{25} & \multirow{2}{*}{0} & Right & 0.0464 & 0.0488 & 0.049 & 0.0196 & 0.0432 & 0.0268 & 0.0376 & 0.045 \\
\hline & & Left & 0.0518 & 0.0528 & 0.0504 & 0.0206 & 0.0444 & 0.0286 & 0.0384 & 0.0454 \\
\hline & \multirow{2}{*}{0.05} & Right & 0.079 & 0.0814 & 0.0782 & 0.042 & 0.072 & 0.0528 & 0.0662 & 0.0778 \\
\hline & & Left & 0.082 & 0.0876 & 0.085 & 0.0436 & 0.0766 & 0.0518 & 0.0712 & 0.08 \\
\hline & \multirow{2}{*}{0.10} & Right & 0.128 & 0.14 & 0.1438 & 0.0864 & 0.1346 & 0.0904 & 0.1188 & 0.1348 \\
\hline & & Left & 0.1344 & 0.1496 & 0.1486 & 0.0838 & 0.1446 & 0.0964 & 0.1284 & 0.146 \\
\hline & \multirow{2}{*}{0.20} & Right & 0.2664 & 0.296 & 0.3116 & 0.2172 & 0.3128 & 0.2292 & 0.2822 & 0.3234 \\
\hline & & Left & 0.2506 & 0.2828 & 0.301 & 0.1998 & 0.3002 & 0.218 & 0.2716 & 0.3034 \\
\hline & \multirow{2}{*}{0.30} & Right & 0.4552 & 0.5014 & 0.5252 & 0.387 & 0.527 & 0.4138 & 0.4806 & 0.5222 \\
\hline & & Left & 0.4518 & 0.5038 & 0.5286 & 0.3996 & 0.532 & 0.4148 & 0.4876 & 0.5236 \\
\hline & \multirow{2}{*}{0.40} & Right & 0.6366 & 0.6862 & 0.7148 & 0.5786 & 0.7182 & 0.6132 & 0.6802 & 0.7174 \\
\hline & & Left & 0.6416 & 0.6862 & 0.7184 & 0.5758 & 0.7176 & 0.6252 & 0.6868 & 0.7158 \\
\hline \multirow{16}{*}{50} & \multirow{2}{*}{0.50} & Right & 0.7898 & 0.8254 & 0.8546 & 0.7426 & 0.8602 & 0.7846 & 0.8364 & 0.857 \\
\hline & & Left & 0.789 & 0.8262 & 0.86 & 0.7432 & 0.862 & 0.7868 & 0.8358 & 0.8584 \\
\hline & \multirow{2}{*}{0} & Right & 0.0476 & 0.047 & 0.0462 & 0.0318 & 0.0428 & 0.0308 & 0.0422 & 0.044 \\
\hline & & Left & 0.0496 & 0.0486 & 0.0486 & 0.033 & 0.0418 & 0.0322 & 0.043 & 0.0456 \\
\hline & \multirow{2}{*}{0.05} & Right & 0.0986 & 0.1044 & 0.1094 & 0.0856 & 0.1072 & 0.0796 & 0.1008 & 0.1096 \\
\hline & & Left & 0.1002 & 0.1064 & 0.109 & 0.0832 & 0.1036 & 0.074 & 0.0976 & 0.1084 \\
\hline & \multirow{2}{*}{0.10} & Right & 0.189 & 0.2124 & 0.2294 & 0.193 & 0.2244 & 0.169 & 0.21 & 0.2286 \\
\hline & & Left & 0.1786 & 0.202 & 0.223 & 0.1886 & 0.228 & 0.1696 & 0.2078 & 0.2324 \\
\hline & \multirow{2}{*}{0.20} & Right & 0.4146 & 0.464 & 0.5028 & 0.4566 & 0.5214 & 0.4264 & 0.4928 & 0.5132 \\
\hline & & Left & 0.4142 & 0.472 & 0.5146 & 0.4698 & 0.5322 & 0.4358 & 0.5012 & 0.5228 \\
\hline & \multirow{2}{*}{0.30} & Right & 0.6758 & 0.742 & 0.7906 & 0.748 & 0.8104 & 0.729 & 0.7836 & 0.7984 \\
\hline & & Left & 0.6822 & 0.748 & 0.7888 & 0.7388 & 0.805 & 0.7194 & 0.7764 & 0.7902 \\
\hline & \multirow{2}{*}{0.40} & Right & 0.878 & 0.918 & 0.9408 & 0.9082 & 0.9496 & 0.9142 & 0.9392 & 0.9444 \\
\hline & & Left & 0.8718 & 0.9122 & 0.9372 & 0.912 & 0.949 & 0.9118 & 0.9358 & 0.9406 \\
\hline & \multirow{2}{*}{0.50} & Right & 0.9654 & 0.977 & 0.9882 & 0.9768 & 0.9888 & 0.9778 & 0.9856 & 0.9872 \\
\hline & & Left & 0.959 & 0.9762 & 0.9862 & 0.9786 & 0.9902 & 0.9782 & 0.986 & 0.9898 \\
\hline
\end{tabular}

Tables 4 through 9 give the simulated levels and powers of the tests, under each model in table 1. Four main results can be deduced from these tables and lead to concluding that under skewed models, the proposed test procedure, Sol(YJ), outperforms all competitor tests whether those based on the original scale or those based on the transformed scale.

Result(1) On the original scale, among the five tests under consideration (T(Orig), NS(Orig), W(Orig), Sign, and Baklizi), when the sampled population has a skewed distribution, the sign and the Baklizi tests are the only choices when the alternative takes the direction of the longer tail. In this case, the results show that the other three tests, $\mathrm{T}($ Orig), NS(Orig), and W(Orig), are liberal and invalid, in the sense of rejecting the true model with a higher percentage of times than the specified nominal level. On the other hand, when the alternative takes the direction of the shorter tail, the
Baklizi test outperforms the other four tests, $\mathrm{T}$ (Orig), NS(Orig), W(Orig), and Sign, since they appear to be conservatives and have poor power properties.

Result(2) On the transformed scale, while W(Hal) dominates the $\mathrm{T}(\mathrm{Hal})$ test, the proposed test procedure, Sol(YJ), outperforms both $\mathrm{W}(\mathrm{Hal})$ and $\mathrm{T}(\mathrm{Hal})$.

Result(3) In general (on both original and transformed scales), the proposed test procedure, Sol(YJ), outperforms the sign and Baklizi tests, which, from result(1), are the best of the five test procedures on the original scale.

Result(4) The proposed test procedure, Sol(YJ), significantly improves over the other tests under contiguous alternatives (those which are close to $\mathrm{H}_{0}$ ). This can be recognized when comparing the empirical powers under the first shift from the null model. 
Table 4. Empirical levels and Powers of the Weibull(2.5) distribution.

\begin{tabular}{|c|c|c|c|c|c|c|c|c|c|c|}
\hline $\mathbf{n}$ & $\delta$ & $\mathrm{H}_{1}$ & T(Orig) & NS(Orig) & W(Orig) & Sign & Baklizi & T(Hal) & W(Hal) & Sol(YJ) \\
\hline \multirow{14}{*}{25} & \multirow{2}{*}{0} & Right & 0.0782 & 0.0752 & 0.0594 & 0.0204 & 0.0506 & 0.0222 & 0.0312 & 0.0446 \\
\hline & & Left & 0.0316 & 0.032 & 0.0366 & 0.0234 & 0.0408 & 0.0316 & 0.0442 & 0.0516 \\
\hline & \multirow{2}{*}{0.05} & Right & 0.1156 & 0.1118 & 0.0952 & 0.0304 & 0.0772 & 0.0394 & 0.054 & 0.067 \\
\hline & & Left & 0.0538 & 0.054 & 0.0612 & 0.0352 & 0.0578 & 0.048 & 0.0622 & 0.0726 \\
\hline & \multirow{2}{*}{0.10} & Right & 0.176 & 0.166 & 0.1416 & 0.043 & 0.1136 & 0.0554 & 0.0736 & 0.102 \\
\hline & & Left & 0.0762 & 0.078 & 0.0838 & 0.0482 & 0.085 & 0.0656 & 0.0862 & 0.0992 \\
\hline & \multirow{2}{*}{0.20} & Right & 0.3306 & 0.3226 & 0.2738 & 0.1046 & 0.2266 & 0.1322 & 0.1652 & 0.2028 \\
\hline & & Left & 0.1684 & 0.1736 & 0.185 & 0.0998 & 0.172 & 0.1352 & 0.1728 & 0.1946 \\
\hline & \multirow{2}{*}{0.30} & Right & 0.5434 & 0.5236 & 0.4652 & 0.1858 & 0.3838 & 0.2466 & 0.2924 & 0.3602 \\
\hline & & Left & 0.3234 & 0.325 & 0.3378 & 0.1808 & 0.3136 & 0.2614 & 0.3042 & 0.3344 \\
\hline & \multirow{2}{*}{0.40} & Right & 0.7336 & 0.717 & 0.655 & 0.316 & 0.5562 & 0.3948 & 0.4502 & 0.5282 \\
\hline & & Left & 0.5004 & 0.4988 & 0.5084 & 0.2864 & 0.4736 & 0.4076 & 0.458 & 0.4932 \\
\hline & \multirow{2}{*}{0.50} & Right & 0.8778 & 0.865 & 0.8188 & 0.4626 & 0.7156 & 0.5596 & 0.623 & 0.6992 \\
\hline & & Left & 0.6642 & 0.6584 & 0.6648 & 0.4136 & 0.6232 & 0.5414 & 0.591 & 0.6334 \\
\hline \multirow{14}{*}{50} & \multirow{2}{*}{0} & Right & 0.1062 & 0.1036 & 0.073 & 0.031 & 0.0542 & 0.0274 & 0.0376 & 0.043 \\
\hline & & Left & 0.0204 & 0.0196 & 0.029 & 0.0316 & 0.0356 & 0.0356 & 0.0474 & 0.0474 \\
\hline & \multirow{2}{*}{0.05} & Right & 0.1792 & 0.1712 & 0.1308 & 0.0532 & 0.097 & 0.0492 & 0.0696 & 0.0786 \\
\hline & & Left & 0.047 & 0.0476 & 0.0636 & 0.0596 & 0.0724 & 0.068 & 0.0838 & 0.0832 \\
\hline & \multirow{2}{*}{0.10} & Right & 0.2948 & 0.2854 & 0.2276 & 0.1048 & 0.1734 & 0.0958 & 0.1262 & 0.1416 \\
\hline & & Left & 0.09 & 0.0928 & 0.1176 & 0.098 & 0.1266 & 0.1192 & 0.1464 & 0.1456 \\
\hline & \multirow{2}{*}{0.20} & Right & 0.5682 & 0.5552 & 0.4656 & 0.2154 & 0.3528 & 0.2324 & 0.2776 & 0.3124 \\
\hline & & Left & 0.2516 & 0.2508 & 0.2912 & 0.2102 & 0.2804 & 0.278 & 0.3168 & 0.311 \\
\hline & \multirow{2}{*}{0.30} & Right & 0.8148 & 0.8002 & 0.7228 & 0.4108 & 0.5666 & 0.448 & 0.5066 & 0.5466 \\
\hline & & Left & 0.5108 & 0.5124 & 0.5496 & 0.3988 & 0.5232 & 0.501 & 0.5506 & 0.5392 \\
\hline & \multirow{2}{*}{0.40} & Right & 0.954 & 0.9456 & 0.9098 & 0.6314 & 0.7666 & 0.6976 & 0.7514 & 0.7726 \\
\hline & & Left & 0.7556 & 0.7518 & 0.7784 & 0.597 & 0.7444 & 0.7172 & 0.7586 & 0.7406 \\
\hline & \multirow{2}{*}{0.50} & Right & 0.9912 & 0.988 & 0.975 & 0.8162 & 0.8974 & 0.8752 & 0.9024 & 0.917 \\
\hline & & Left & 0.9174 & 0.9156 & 0.9244 & 0.7814 & 0.903 & 0.8816 & 0.9048 & 0.8962 \\
\hline
\end{tabular}

Table 5. Empirical levels and Powers of the Weibull (2) distribution.

\begin{tabular}{|c|c|c|c|c|c|c|c|c|c|c|}
\hline n & $\delta$ & $\mathrm{H}_{1}$ & T(Orig) & NS(Orig) & W(Orig) & Sign & Baklizi & T(Hal) & W(Hal) & Sol(YJ) \\
\hline \multirow{12}{*}{25} & \multirow{2}{*}{0} & Right & 0.1132 & 0.1052 & 0.0794 & 0.021 & 0.0572 & 0.0208 & 0.031 & 0.0458 \\
\hline & & Left & 0.0194 & 0.0222 & 0.0294 & 0.0222 & 0.0338 & 0.033 & 0.0462 & 0.0516 \\
\hline & \multirow{2}{*}{0.05} & Right & 0.1704 & 0.1556 & 0.1186 & 0.0354 & 0.0868 & 0.0402 & 0.053 & 0.072 \\
\hline & & Left & 0.0388 & 0.0388 & 0.0496 & 0.0388 & 0.0544 & 0.0554 & 0.0696 & 0.0738 \\
\hline & \multirow{2}{*}{0.10} & Right & 0.2446 & 0.2292 & 0.1766 & 0.0458 & 0.1234 & 0.0544 & 0.0732 & 0.1052 \\
\hline & & Left & 0.0544 & 0.055 & 0.0708 & 0.0492 & 0.075 & 0.0726 & 0.0942 & 0.1076 \\
\hline & \multirow{2}{*}{0.20} & Right & 0.4294 & 0.3954 & 0.33 & 0.1068 & 0.2388 & 0.1334 & 0.1676 & 0.2206 \\
\hline & & Left & 0.1246 & 0.1252 & 0.1544 & 0.0974 & 0.1494 & 0.1466 & 0.1752 & 0.1932 \\
\hline & \multirow{2}{*}{0.30} & Right & 0.6606 & 0.6198 & 0.541 & 0.1962 & 0.3884 & 0.2458 & 0.2932 & 0.3774 \\
\hline & & Left & 0.256 & 0.255 & 0.2916 & 0.1906 & 0.2754 & 0.2714 & 0.3106 & 0.329 \\
\hline & \multirow{2}{*}{0.40} & Right & 0.8322 & 0.806 & 0.7376 & 0.3452 & 0.5588 & 0.4022 & 0.4614 & 0.5672 \\
\hline & & Left & 0.4064 & 0.41 & 0.4418 & 0.2868 & 0.4146 & 0.3972 & 0.4492 & 0.4734 \\
\hline \multirow{15}{*}{50} & \multirow{2}{*}{0.50} & Right & 0.9386 & 0.9198 & 0.8732 & 0.5078 & 0.7098 & 0.5818 & 0.6378 & 0.7482 \\
\hline & & Left & 0.5822 & 0.5814 & 0.6148 & 0.4092 & 0.5734 & 0.5492 & 0.6004 & 0.6224 \\
\hline & 0 & Left & 0.007 & 0.0076 & 0.0206 & 0.0292 & 0.0306 & 0.0426 & 0.0546 & 0.0496 \\
\hline & \multirow{2}{*}{0.05} & Right & 0.2916 & 0.2704 & 0.1792 & 0.0564 & 0.0996 & 0.0464 & 0.0634 & 0.0772 \\
\hline & & Left & 0.0224 & 0.0244 & 0.0438 & 0.0594 & 0.0638 & 0.0778 & 0.0972 & 0.0906 \\
\hline & \multirow{2}{*}{0.10} & Right & 0.4438 & 0.4088 & 0.2986 & 0.1014 & 0.168 & 0.0918 & 0.1198 & 0.1484 \\
\hline & & Left & 0.0484 & 0.0524 & 0.0834 & 0.0948 & 0.105 & 0.1238 & 0.1516 & 0.1436 \\
\hline & \multirow{2}{*}{0.20} & Right & 0.728 & 0.683 & 0.564 & 0.2234 & 0.3184 & 0.2214 & 0.2704 & 0.3232 \\
\hline & & Left & 0.1582 & 0.1568 & 0.2346 & 0.2228 & 0.252 & 0.293 & 0.333 & 0.3182 \\
\hline & \multirow{2}{*}{0.30} & Right & 0.9102 & 0.8866 & 0.8124 & 0.4276 & 0.536 & 0.446 & 0.5088 & 0.5698 \\
\hline & & Left & 0.3746 & 0.368 & 0.4684 & 0.3996 & 0.46 & 0.5168 & 0.565 & 0.5374 \\
\hline & \multirow{2}{*}{0.40} & Right & 0.987 & 0.9796 & 0.9516 & 0.6646 & 0.7346 & 0.7084 & 0.7556 & 0.8004 \\
\hline & & Left & 0.631 & 0.629 & 0.7084 & 0.5896 & 0.675 & 0.7262 & 0.7642 & 0.7284 \\
\hline & \multirow{2}{*}{0.50} & Right & 0.9984 & 0.9968 & 0.9902 & 0.8454 & 0.8822 & 0.8878 & 0.9132 & 0.934 \\
\hline & & Left & 0.842 & 0.843 & 0.8866 & 0.7722 & 0.8572 & 0.882 & 0.9074 & 0.8878 \\
\hline
\end{tabular}


Table 6. Empirical levels and Powers of the Gamma(4) distribution.

\begin{tabular}{|c|c|c|c|c|c|c|c|c|c|c|}
\hline $\mathbf{n}$ & $\delta$ & $\mathrm{H}_{1}$ & T(Orig) & NS(Orig) & W(Orig) & Sign & Baklizi & T(Hal) & W(Hal) & Sol(YJ) \\
\hline \multirow{14}{*}{25} & \multirow{2}{*}{0} & Right & 0.1706 & 0.1458 & 0.101 & 0.0242 & 0.0604 & 0.023 & 0.0314 & 0.044 \\
\hline & & Left & 0.0164 & 0.0178 & 0.0276 & 0.0198 & 0.0292 & 0.0348 & 0.0472 & 0.0488 \\
\hline & \multirow{2}{*}{0.05} & Right & 0.2488 & 0.2126 & 0.1594 & 0.0376 & 0.094 & 0.0406 & 0.0562 & 0.075 \\
\hline & & Left & 0.0226 & 0.026 & 0.0378 & 0.034 & 0.0462 & 0.0536 & 0.0714 & 0.073 \\
\hline & \multirow{2}{*}{0.10} & Right & 0.3284 & 0.2886 & 0.2198 & 0.0558 & 0.1262 & 0.059 & 0.0782 & 0.1048 \\
\hline & & Left & 0.0424 & 0.0472 & 0.0708 & 0.06 & 0.0794 & 0.0902 & 0.1126 & 0.1142 \\
\hline & \multirow{2}{*}{0.20} & Right & 0.5548 & 0.4978 & 0.4168 & 0.121 & 0.2508 & 0.1404 & 0.1726 & 0.225 \\
\hline & & Left & 0.1008 & 0.1126 & 0.1468 & 0.1112 & 0.1556 & 0.1776 & 0.2146 & 0.2232 \\
\hline & \multirow{2}{*}{0.30} & Right & 0.7574 & 0.702 & 0.6246 & 0.2468 & 0.4142 & 0.2832 & 0.3324 & 0.3986 \\
\hline & & Left & 0.2046 & 0.2156 & 0.2684 & 0.2054 & 0.272 & 0.2934 & 0.34 & 0.348 \\
\hline & \multirow{2}{*}{0.40} & Right & 0.911 & 0.8752 & 0.8172 & 0.4036 & 0.5822 & 0.4658 & 0.5312 & 0.6104 \\
\hline & & Left & 0.3668 & 0.3776 & 0.4418 & 0.3326 & 0.4344 & 0.4532 & 0.508 & 0.52 \\
\hline & \multirow{2}{*}{0.50} & Right & 0.9758 & 0.9626 & 0.9322 & 0.609 & 0.752 & 0.672 & 0.7234 & 0.7948 \\
\hline & & Left & 0.5144 & 0.5242 & 0.5916 & 0.4498 & 0.5658 & 0.5902 & 0.638 & 0.6524 \\
\hline \multirow{14}{*}{50} & \multirow{2}{*}{0} & Right & 0.273 & 0.213 & 0.1328 & 0.0342 & 0.0502 & 0.0208 & 0.0304 & 0.0392 \\
\hline & & Left & 0.0052 & 0.0072 & 0.016 & 0.0306 & 0.032 & 0.0432 & 0.0548 & 0.0494 \\
\hline & \multirow{2}{*}{0.05} & Right & 0.435 & 0.358 & 0.2472 & 0.0612 & 0.093 & 0.0466 & 0.0622 & 0.0774 \\
\hline & & Left & 0.0096 & 0.0128 & 0.0294 & 0.0554 & 0.0572 & 0.0802 & 0.1028 & 0.0904 \\
\hline & \multirow{2}{*}{0.10} & Right & 0.582 & 0.498 & 0.3636 & 0.1088 & 0.151 & 0.0874 & 0.1122 & 0.1362 \\
\hline & & Left & 0.0242 & 0.034 & 0.0688 & 0.0992 & 0.1034 & 0.1414 & 0.173 & 0.1586 \\
\hline & \multirow{2}{*}{0.20} & Right & 0.8372 & 0.7714 & 0.6586 & 0.2648 & 0.3258 & 0.2388 & 0.2966 & 0.3368 \\
\hline & & Left & 0.104 & 0.1252 & 0.2032 & 0.2438 & 0.2576 & 0.324 & 0.3782 & 0.3504 \\
\hline & \multirow{2}{*}{0.30} & Right & 0.9698 & 0.9468 & 0.897 & 0.5112 & 0.5662 & 0.5178 & 0.5792 & 0.6278 \\
\hline & & Left & 0.2748 & 0.3062 & 0.438 & 0.4378 & 0.4662 & 0.5686 & 0.6172 & 0.5798 \\
\hline & \multirow{2}{*}{0.40} & Right & 0.9954 & 0.9908 & 0.9774 & 0.7556 & 0.7826 & 0.7808 & 0.8238 & 0.8532 \\
\hline & & Left & 0.5286 & 0.5528 & 0.686 & 0.6462 & 0.6828 & 0.7814 & 0.8168 & 0.786 \\
\hline & \multirow{2}{*}{0.50} & Right & 1 & 0.9996 & 0.9976 & 0.921 & 0.9306 & 0.939 & 0.9536 & 0.967 \\
\hline & & Left & 0.7496 & 0.7674 & 0.862 & 0.8016 & 0.8422 & 0.9058 & 0.9268 & 0.9068 \\
\hline
\end{tabular}

Table 7. Empirical levels and Powers of the Extreme Value distribution.

\begin{tabular}{|c|c|c|c|c|c|c|c|c|c|c|}
\hline n & $\delta$ & $\mathrm{H}_{1}$ & T(Orig) & NS(Orig) & W(Orig) & Sign & Baklizi & T(Hal) & W(Hal) & Sol(YJ) \\
\hline \multirow{12}{*}{25} & \multirow{2}{*}{0} & Right & 0.1596 & 0.1328 & 0.1006 & 0.0234 & 0.0586 & 0.0244 & 0.0354 & 0.0478 \\
\hline & & Left & 0.012 & 0.0168 & 0.0224 & 0.0192 & 0.0272 & 0.03 & 0.04 & 0.045 \\
\hline & \multirow{2}{*}{0.05} & Right & 0.2318 & 0.1952 & 0.144 & 0.035 & 0.0836 & 0.0352 & 0.053 & 0.0714 \\
\hline & & Left & 0.0218 & 0.0264 & 0.0372 & 0.035 & 0.0466 & 0.047 & 0.0634 & 0.0682 \\
\hline & \multirow{2}{*}{0.10} & Right & 0.3274 & 0.281 & 0.2258 & 0.0632 & 0.138 & 0.0712 & 0.0938 & 0.1188 \\
\hline & & Left & 0.0444 & 0.0494 & 0.07 & 0.0528 & 0.0768 & 0.0902 & 0.1106 & 0.1134 \\
\hline & \multirow{2}{*}{0.20} & Right & 0.5574 & 0.4972 & 0.4234 & 0.1326 & 0.2596 & 0.1634 & 0.2048 & 0.2506 \\
\hline & & Left & 0.1048 & 0.1206 & 0.1574 & 0.12 & 0.1674 & 0.177 & 0.221 & 0.2308 \\
\hline & \multirow{2}{*}{0.30} & Right & 0.7666 & 0.719 & 0.6386 & 0.2592 & 0.427 & 0.3166 & 0.372 & 0.4276 \\
\hline & & Left & 0.215 & 0.234 & 0.2912 & 0.219 & 0.2952 & 0.3138 & 0.3618 & 0.3734 \\
\hline & \multirow{2}{*}{0.40} & Right & 0.9168 & 0.8836 & 0.8336 & 0.4522 & 0.625 & 0.531 & 0.5958 & 0.6704 \\
\hline & & Left & 0.3648 & 0.396 & 0.4674 & 0.3608 & 0.4648 & 0.4802 & 0.5338 & 0.5532 \\
\hline \multirow{15}{*}{50} & \multirow{2}{*}{0.50} & Right & 0.9768 & 0.9656 & 0.946 & 0.6576 & 0.7934 & 0.7424 & 0.7926 & 0.8464 \\
\hline & & Left & 0.5378 & 0.5668 & 0.6392 & 0.4942 & 0.619 & 0.6384 & 0.6886 & 0.7028 \\
\hline & 0 & Left & 0.0042 & 0.0076 & 0.019 & 0.0338 & 0.035 & 0.0398 & 0.053 & 0.0514 \\
\hline & \multirow{2}{*}{0.05} & Right & 0.423 & 0.3428 & 0.2322 & 0.0612 & 0.0882 & 0.0562 & 0.0764 & 0.0876 \\
\hline & & Left & 0.0104 & 0.0158 & 0.0354 & 0.061 & 0.0638 & 0.0794 & 0.1026 & 0.0924 \\
\hline & \multirow{2}{*}{0.10} & Right & 0.5698 & 0.4816 & 0.3578 & 0.1128 & 0.1526 & 0.1034 & 0.133 & 0.1564 \\
\hline & & Left & 0.0274 & 0.0372 & 0.077 & 0.1082 & 0.114 & 0.144 & 0.1716 & 0.167 \\
\hline & \multirow{2}{*}{0.20} & Right & 0.8534 & 0.789 & 0.6782 & 0.2972 & 0.3572 & 0.3072 & 0.3634 & 0.3914 \\
\hline & & Left & 0.099 & 0.1306 & 0.2216 & 0.2644 & 0.2798 & 0.3422 & 0.393 & 0.373 \\
\hline & \multirow{2}{*}{0.30} & Right & 0.9702 & 0.9458 & 0.8984 & 0.5598 & 0.6058 & 0.5882 & 0.6432 & 0.6722 \\
\hline & & Left & 0.2744 & 0.3264 & 0.4672 & 0.4686 & 0.5024 & 0.5858 & 0.6368 & 0.615 \\
\hline & \multirow{2}{*}{0.40} & Right & 0.999 & 0.9952 & 0.9834 & 0.804 & 0.8288 & 0.8478 & 0.8856 & 0.8986 \\
\hline & & Left & 0.5166 & 0.5728 & 0.7058 & 0.6858 & 0.7212 & 0.8008 & 0.8398 & 0.814 \\
\hline & \multirow{2}{*}{0.50} & Right & 0.9998 & 0.9996 & 0.9986 & 0.9428 & 0.9528 & 0.97 & 0.979 & 0.984 \\
\hline & & Left & 0.7352 & 0.7796 & 0.875 & 0.8342 & 0.8682 & 0.9168 & 0.9376 & 0.923 \\
\hline
\end{tabular}


Table 8. Empirical levels and Powers of the Gamma(2) distribution.

\begin{tabular}{|c|c|c|c|c|c|c|c|c|c|c|}
\hline n & $\delta$ & $\mathrm{H}_{1}$ & T(Orig) & NS(Orig) & W(Orig) & Sign & Baklizi & T(Hal) & W(Hal) & Sol(YJ) \\
\hline \multirow{14}{*}{25} & \multirow{2}{*}{0} & Right & 0.2452 & 0.19 & 0.1324 & 0.0214 & 0.0556 & 0.0196 & 0.0274 & 0.0448 \\
\hline & & Left & 0.0072 & 0.0092 & 0.016 & 0.0214 & 0.0266 & 0.0398 & 0.0488 & 0.051 \\
\hline & \multirow{2}{*}{0.05} & Right & 0.3564 & 0.288 & 0.2114 & 0.0378 & 0.0848 & 0.0372 & 0.0494 & 0.0778 \\
\hline & & Left & 0.0138 & 0.017 & 0.0312 & 0.0392 & 0.0452 & 0.0646 & 0.0822 & 0.0768 \\
\hline & \multirow{2}{*}{0.10} & Right & 0.466 & 0.3744 & 0.2844 & 0.0558 & 0.1176 & 0.057 & 0.082 & 0.123 \\
\hline & & Left & 0.0224 & 0.0282 & 0.0486 & 0.0552 & 0.0642 & 0.0954 & 0.1162 & 0.1148 \\
\hline & \multirow{2}{*}{0.20} & Right & 0.703 & 0.6146 & 0.5086 & 0.1412 & 0.238 & 0.1492 & 0.1858 & 0.2674 \\
\hline & & Left & 0.0692 & 0.0812 & 0.1226 & 0.1192 & 0.1388 & 0.1952 & 0.2266 & 0.2212 \\
\hline & \multirow{2}{*}{0.30} & Right & 0.896 & 0.8286 & 0.7522 & 0.288 & 0.4066 & 0.3218 & 0.3816 & 0.4972 \\
\hline & & Left & 0.1418 & 0.1592 & 0.2228 & 0.1986 & 0.2334 & 0.3286 & 0.3706 & 0.3604 \\
\hline & \multirow{2}{*}{0.40} & Right & 0.9742 & 0.9464 & 0.9076 & 0.4886 & 0.602 & 0.5484 & 0.617 & 0.7338 \\
\hline & & Left & 0.2686 & 0.2902 & 0.3806 & 0.3246 & 0.3772 & 0.4798 & 0.527 & 0.518 \\
\hline & \multirow{2}{*}{0.50} & Right & 0.9966 & 0.9908 & 0.9818 & 0.712 & 0.7848 & 0.7758 & 0.8194 & 0.9038 \\
\hline & & Left & 0.4146 & 0.4376 & 0.5366 & 0.4528 & 0.5186 & 0.6246 & 0.671 & 0.6556 \\
\hline \multirow{13}{*}{50} & 0 & Left & 0.0012 & 0.0018 & 0.008 & 0.0292 & 0.0292 & 0.0494 & 0.0598 & 0.0452 \\
\hline & \multirow{2}{*}{0.05} & Right & 0.6252 & 0.4836 & 0.318 & 0.0612 & 0.0738 & 0.039 & 0.0538 & 0.0816 \\
\hline & & Left & 0.004 & 0.0076 & 0.023 & 0.0604 & 0.0606 & 0.0952 & 0.1176 & 0.096 \\
\hline & \multirow{2}{*}{0.10} & Right & 0.7754 & 0.643 & 0.4788 & 0.1142 & 0.1296 & 0.0878 & 0.1166 & 0.1636 \\
\hline & & Left & 0.0102 & 0.0168 & 0.047 & 0.1146 & 0.1152 & 0.1814 & 0.2112 & 0.1822 \\
\hline & \multirow{2}{*}{0.20} & Right & 0.9494 & 0.888 & 0.7882 & 0.3082 & 0.3258 & 0.269 & 0.3246 & 0.4066 \\
\hline & & Left & 0.056 & 0.0788 & 0.1652 & 0.2432 & 0.245 & 0.3646 & 0.4072 & 0.3498 \\
\hline & \multirow{2}{*}{0.30} & Right & 0.9948 & 0.9842 & 0.956 & 0.5832 & 0.596 & 0.5748 & 0.64 & 0.7244 \\
\hline & & Left & 0.1806 & 0.2116 & 0.3706 & 0.4618 & 0.4664 & 0.635 & 0.6724 & 0.6016 \\
\hline & \multirow{2}{*}{0.40} & Right & 0.9996 & 0.9988 & 0.9946 & 0.827 & 0.8322 & 0.8438 & 0.8796 & 0.9218 \\
\hline & & Left & 0.3694 & 0.4292 & 0.6208 & 0.6592 & 0.667 & 0.8102 & 0.8392 & 0.7888 \\
\hline & \multirow{2}{*}{0.50} & Right & 1 & 1 & 0.9998 & 0.9668 & 0.968 & 0.976 & 0.984 & 0.992 \\
\hline & & Left & 0.609 & 0.6564 & 0.8158 & 0.8192 & 0.8272 & 0.9246 & 0.9386 & 0.9034 \\
\hline
\end{tabular}

Table 9. Empirical levels and Powers of the Lognormal distribution.

\begin{tabular}{|c|c|c|c|c|c|c|c|c|c|c|}
\hline $\mathbf{n}$ & $\delta$ & $\mathrm{H}_{1}$ & T(Orig) & NS(Orig) & W(Orig) & Sign & Baklizi & T(Hal) & W(Hal) & Sol(YJ) \\
\hline \multirow{11}{*}{25} & \multirow{2}{*}{0} & Right & 0.4728 & 0.3116 & 0.2084 & 0.0216 & 0.0282 & 0.018 & 0.0254 & 0.0584 \\
\hline & & Left & 0.0016 & 0.0026 & 0.0072 & 0.0202 & 0.0202 & 0.0452 & 0.0548 & 0.0442 \\
\hline & \multirow{2}{*}{0.05} & Right & 0.6724 & 0.5042 & 0.386 & 0.0526 & 0.0688 & 0.0534 & 0.073 & 0.1498 \\
\hline & & Left & 0.0042 & 0.011 & 0.0248 & 0.0546 & 0.0558 & 0.1054 & 0.1288 & 0.1064 \\
\hline & \multirow{2}{*}{0.10} & Right & 0.844 & 0.7304 & 0.6106 & 0.1538 & 0.1724 & 0.1556 & 0.1942 & 0.3388 \\
\hline & & Left & 0.0126 & 0.0252 & 0.0576 & 0.1108 & 0.1124 & 0.2066 & 0.2372 & 0.2028 \\
\hline & 0.20 & Left & 0.0652 & 0.1122 & 0.2022 & 0.2688 & 0.2748 & 0.4552 & 0.4924 & 0.4408 \\
\hline & \multirow{2}{*}{0.30} & Right & 0.9966 & 1 & 1 & 0.9756 & 0.9774 & 0.99 & 0.9938 & 0.998 \\
\hline & & Left & 0.1608 & 0.2488 & 0.3892 & 0.4714 & 0.48 & 0.705 & 0.7318 & 0.6672 \\
\hline & \multirow{2}{*}{0.40} & Right & 0.9974 & 1 & 1 & 1 & 1 & 1 & 1 & 1 \\
\hline & & Left & 0.3068 & 0.4282 & 0.5946 & 0.6608 & 0.6716 & 0.8594 & 0.8802 & 0.8214 \\
\hline \multirow{16}{*}{50} & \multirow{2}{*}{0.50} & Right & 0.9992 & 1 & 1 & 1 & 1 & 1 & 1 & 1 \\
\hline & & Left & 0.4366 & 0.5904 & 0.749 & 0.7938 & 0.7994 & 0.9326 & 0.9436 & 0.9054 \\
\hline & \multirow{2}{*}{0} & Right & 0.8382 & 0.548 & 0.3428 & 0.0332 & 0.0332 & 0.0142 & 0.022 & 0.051 \\
\hline & & Left & 0 & 0.0002 & 0.0022 & 0.0346 & 0.0346 & 0.0616 & 0.0752 & 0.0534 \\
\hline & \multirow{2}{*}{0.05} & Right & 0.9494 & 0.811 & 0.6482 & 0.1042 & 0.1044 & 0.0734 & 0.1016 & 0.185 \\
\hline & & Left & 0.0008 & 0.0048 & 0.0176 & 0.104 & 0.104 & 0.1912 & 0.2146 & 0.1592 \\
\hline & \multirow{2}{*}{0.10} & Right & 0.9896 & 0.9528 & 0.8812 & 0.3116 & 0.312 & 0.2754 & 0.3304 & 0.4712 \\
\hline & & Left & 0.003 & 0.016 & 0.0586 & 0.23 & 0.23 & 0.3976 & 0.4362 & 0.3182 \\
\hline & \multirow{2}{*}{0.20} & Right & 0.999 & 1 & 0.9992 & 0.9058 & 0.906 & 0.922 & 0.9394 & 0.962 \\
\hline & & Left & 0.0286 & 0.1096 & 0.275 & 0.5666 & 0.5668 & 0.7872 & 0.8124 & 0.6934 \\
\hline & \multirow{2}{*}{0.30} & Right & 0.9998 & 1 & 1 & 1 & 1 & 1 & 1 & 1 \\
\hline & & Left & 0.1424 & 0.3386 & 0.5982 & 0.8274 & 0.8274 & 0.9554 & 0.964 & 0.9018 \\
\hline & \multirow{2}{*}{0.40} & Right & 0.9998 & 1 & 1 & 1 & 1 & 1 & 1 & 1 \\
\hline & & Left & 0.327 & 0.6116 & 0.8494 & 0.9506 & 0.9506 & 0.9932 & 0.9946 & 0.9764 \\
\hline & \multirow{2}{*}{0.50} & Right & 1 & 1 & 1 & 1 & 1 & 1 & 1 & 1 \\
\hline & & Left & 0.541 & 0.8228 & 0.9506 & 0.983 & 0.983 & 0.9988 & 0.9988 & 0.9924 \\
\hline
\end{tabular}




\section{References}

[1] Baklizi, A. (2005). A Continuously Adaptive Rank Test for Shift in Location. Australian and New Zealand Journal of Statistics, 47, 203-209.

[2] Box, G. E. P. and Cox, D. R. (1964). Analysis of Transformations. Journal of the Royal Statitical Society, Ser. B, 26, 211-252

[3] Doksum, K. A. and Wong, C. W. (1983). Statistical Tests Based on Transformed Data. Journal of the American Statistical Association, 78, 411-417.

[4] Fraser, D. A. S. (1957b). Most Powerful Rank-Type Tests. Annals of Mathematical Statistics, 28, 1040-1043.

[5] Freidlin, B., Miao, W., and Gastwirth, J. L. (2003). On The Use of the Shapiro-Wilk Test in Two-Stage Adaptive Inference for Paired Data from Moderate to Very Heavy Tailed Distributions. Biometrical Journal, 45, 887-900.

[6] Gastwirth, J. L .(1966). On Robust Procedures. Journal of the American Statistical Association, 61, 929-948.

[7] Halawa, A. M. (1989). Testing for Location after Transformation to Normality. Ph.D. thesis (unpublished), Oregon State University, Oregon, U.S.A.

[8] Halawa, A. M. (2001). A Test of the Median after the Twodomain Transformation. Journal of the Faculty of Commerce for Scientific Research, 38 (1), 29-41.

[9] Harter, H. L. (1961). Expected Values of Normal Order Statistics. Biometrika, 48, 1 and 2, 151-165.

[10] Hollander, M., Wolfe, D. A., and Chicken, E. (2014). Nonparametric Statistical Methods. New York: John Wiley \& Sons.

[11] John, J. A. and Draper, N. R. (1980). An Alternative Family of Transformations. Applied Statistics, 29, 190-197.

[12] Randles, R. H. and Wolfe, D. A. (1979). Introduction to the Theory of Nonparametric Statistics. New York: John Wiley \& Sons.

[13] Randles, R. H., Fligner, M., Policello, G., and Wolfe, D. (1980). An Asymptotically Distribution-Free Test for Symmetry versus Asymmetry. Journal of the American Statistics Association 75 (369), 168-172.

[14] Royston, J. P. (1982). An Extension of Shapiro and Wilk's Test for Normality to Large Samples. Applied Statistics, 31, 115-124.

[15] Shapiro, S. S. and Wilk, M. B. (1965). An Analysis of Variance Test for Normality (Complete Samples). Biometrika, 52, 591-611.

[16] Van Zwet, W. R. (1964). Convex Transformations of Random Variables. Amsterdam, Mathematisch Centrum.

[17] Yeo, I. K. and Johnson, R. A. (2000). A New Family of Power Transformations to Improve Normality and Symmetry. Biometrika, 87, 954-959. 